\title{
Challenge Agent Metabolite Caused Injury Indicator
}

National Cancer Institute

\section{Source}

National Cancer Institute. Challenge Agent Metabolite Caused Injury Indicator. NCI

Thesaurus. Code C158317.

An indication as to whether a metabolite of the chemical challenge agent is known to cause or contribute to the injury or condition of interest. 